Proceedings of the XXIII Conference on Applied Crystallography, Krynica Zdrój, Poland, September 20-24, 2015

\title{
The Application of Laboratory X-Ray Micro-Diffraction to Study the Effects of Clinching Process in Steel Sheets
}

\author{
H. Krztoń $\dot{1}^{a, *}$, J. MUChA ${ }^{b}$ And W. WitKowski ${ }^{b}$ \\ ${ }^{a}$ Instytut Metalurgii Żelaza, Gliwice, Poland \\ ${ }^{b}$ Rzeszów University of Technology, Rzeszów, Poland
}

\begin{abstract}
The application of X-ray micro-diffraction to study the local changes in austenite content in clinching joints made of DP 600 steel is presented. The relations between various parameters of the cold pressing process and the microstructure and the austenite content in the individual parts of the clinching joints are shown.
\end{abstract}

DOI: 10.12693/APhysPolA.130.985

PACS/topics: 61.05.cp, 81.30.Kf, 81.70.Bt, 81.20.Vj

\section{Introduction}

The clinching joining technology (CL) is commonly used in the automotive industry during the assembly processes of sheet metal thin-walled constructions [1, 2]. The joint formation is made by a cold pressing process on a very small area and such parameters of the process as tools geometry and pressing force determine the interlock quality (Fig. 1) [3-5]. Additionally, not only the

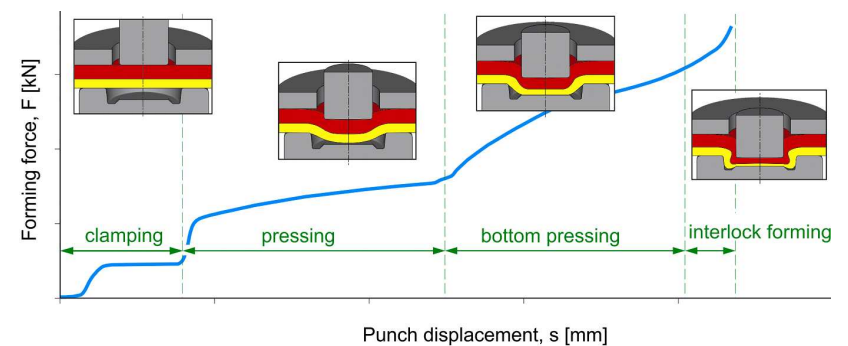

Fig. 1. Schematic view of the forming of a clinching joint along with the changes of forming force during the clinching joint formation. During the joining process, in the joint area, the punch is pressed in the connected materials. The sheet material is pressed gradually in to the cavity die. The sheet metal pressing is continued until the sheet abuts of the die bottom. Then the sheet begins to fill the space between the punch and die cavity. After filling this space and further punch pressing the interlock bottom is intensively pressed. At this pressing stage the interlock is forming by gradual sheets layers pressing.

shape and the geometry of the interlock affect the joint strength but the structural changes in the joint zone as well. In the case of dual phase steels (such as TRIP steels [6]), whose microstructure consists of ferrite and martensite with some amounts of austenite and bainite, during the plastic deformation austenite is transformed to martensite (Table I). X-ray diffraction (XRD) can be

\footnotetext{
* corresponding author; e-mail: hkrzton@imz.pl
}

Components of microstructures.

TABLE I

\begin{tabular}{|c|c|c|c|}
\hline Component & Definition & $\begin{array}{l}\text { Space } \\
\text { group }\end{array}$ & Identification \\
\hline ferrite & $\begin{array}{l}\text { a solid solution of lim- } \\
\text { ited amounts of carbon in } \\
\text { iron or iron alloys with a } \\
\text { body-centered cubic crystal } \\
\text { structure }\end{array}$ & $I m \overline{3} m$ & $\begin{array}{l}\text { ICDD/PDF: } \\
\text { 00-006-0696 }\end{array}$ \\
\hline austenite & $\begin{array}{l}\text { a solid solution of lim- } \\
\text { ited amounts of carbon in } \\
\text { iron or iron alloys with a } \\
\text { face-centered cubic crystal } \\
\text { structure }\end{array}$ & $F m \overline{3} m$ & $\begin{array}{l}\text { ICDD/PDF } \\
\text { (depending } \\
\text { on com- } \\
\text { position) } \\
00-033-0397 \\
00-052-0512 \\
04-018-3211\end{array}$ \\
\hline martensite & $\begin{array}{l}\text { a supersaturated solid so- } \\
\text { lution of carbon in iron } \\
\text { with a body-centered cu- } \\
\text { bic crystal structure or with } \\
\text { a body-centered tetragonal } \\
\text { structure }\end{array}$ & $\begin{array}{l}\text { Im } \overline{3} m \text { or } \\
I 4 / m m m\end{array}$ & $\begin{array}{l}\text { ICDD } / \text { PDF: } \\
\text { 04-019-3347 } \\
\text { (cubic) } \\
\text { 00-044-1290 } \\
\text { (tetragonal) }\end{array}$ \\
\hline bainite & $\begin{array}{l}\text { microstructure component } \\
\text { consisting of bainitic ferrite } \\
\text { and a second component } \\
\text { consisting of layers or islands } \\
\text { of martensite and austenite } \\
\text { in various proportions }\end{array}$ & - & $\begin{array}{l}\text { identification } \\
\text { by micro- } \\
\text { scopic ob- } \\
\text { servation of } \\
\text { microstructure }\end{array}$ \\
\hline
\end{tabular}

successfully applied to study a distribution of residual stresses in the joint interlocks formed by various tools systems $[7,8]$. However, the most often application of XRD technique for steel products is a determination of amount of austenite content. In particular, X-ray laboratory micro-diffraction can be used to study the very local and fine changes in austenite content occurring during a clinching process [9]. In this paper, the forming force and punch diameter impact on the microstructure changes and the austenite distribution in the clinching joints of DP 600 steel are presented.

\section{Experimental}

The joining test was performed for a steel sheet made of DP600 dual-phase steel of thickness $1.0 \mathrm{~mm}$, which is commonly used for producing motorcar bodies. The ba-

TABLE II

Mechanical properties of DP600. Yield stress $R_{e}$ or (0.2), ultimate strength $R_{m}$, and unit elongation $A_{80}$.

\begin{tabular}{c|c|c}
\hline \hline$R_{e \text { or }(0.2)}$ & $R_{m}$ & $A_{80}$ \\
\hline $380 \mathrm{MPa}$ & $600 \mathrm{MPa}$ & $20 \%$
\end{tabular}


The chemical composition [wt.\%] of DP600. TABLE III

\begin{tabular}{c|c|c|c|c|c|c|c|c|c|c}
\hline \hline $\mathrm{C}$ & $\mathrm{Si}$ & $\mathrm{Mn}$ & $\mathrm{P}$ & $\mathrm{S}$ & $\mathrm{Al}$ & $\mathrm{Cr}$ & $\mathrm{Mo}$ & $\mathrm{Ni}$ & $\mathrm{V}$ & $\mathrm{Ti}$ \\
\hline 12 & 30 & 16.6 & 2 & 0.4 & 2 & 50 & 5 & 5 & 4.5 & 0.6
\end{tabular}

TABLE IV

Forming conditions, punch diameter $d[\mathrm{~mm}]$, embossment thickness $X[\mathrm{~mm}]$, and forming force $F_{f}[\mathrm{kN}]$ of the examined clinching joints.

\begin{tabular}{c|c|c|c}
\hline \hline Sample & $d$ & $X$ & $F_{f}$ \\
\hline A & 5.6 & 1.25 & 101.5 \\
B & 5.2 & 0.75 & 96.4 \\
C & 4.8 & 0.75 & 63.5 \\
D & 4.8 & 0.60 & 71.0
\end{tabular}

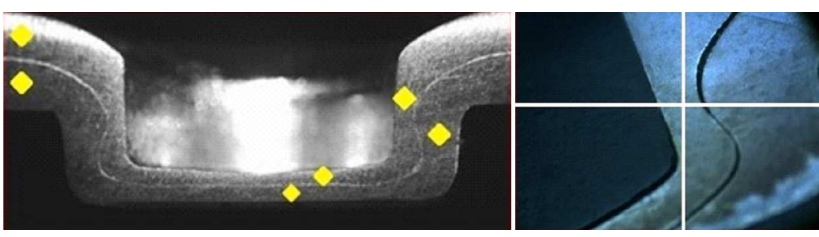

Fig. 2. Scheme of the XRD measurements. A clinching joint - the approximate positions of the measured areas (left). On the right a surface of a joint - light blue, the resin - black, as seen in the diffractometer camera, with the position of the center of the primary beam (the intersection of the white perpendicular lines).

sic mechanical properties are presented in Table II, and the chemical composition is shown in Table III. The conditions of forming are given in Table IV. The XRD data were collected using a PANalytical Empyrean ThetaTheta diffractometer, equipped with a micro-diffraction attachment, a cobalt X-ray tube $(\lambda=0.17903 \mathrm{~nm}, 40 \mathrm{kV}$, $40 \mathrm{~mA}$ ) with a point focus, an iron filter, placed between the X-ray tube and a specimen, and a PIXcel detector in 1D mode. Two monocapillaries of inner diameters of $0.3 \mathrm{~mm}$ and of $0.1 \mathrm{~mm}$, respectively, were used on the primary beam. The size of the diameters of the beam on the samples was approximately $0.4 \mathrm{~mm}$ and $0.15 \mathrm{~mm}$, respectively. The angular range was $47-126^{\circ} 2 \theta$ (both austenite and ferrite/martensite phases have got no reflections below $50^{\circ} 2 \theta$ for Co radiation) with a step size of $0.02626^{\circ} 2 \theta$ and step counting time of $500 \mathrm{~s}$. According to ICDD data, there are four reflections of each phase (austenite and ferrite) in this range, the presence of them depending on the content of phases. There are usually three pairs of reflections (three of austenite and three of ferrite/martensite) used in calculations to minimize the influence of preferred orientation. The surfaces of the steel samples were prepared for X-ray diffraction experiments by cutting, polishing and finally etching to eliminate the influence of mechanical treatments on the stability of austenite. Then they were placed on a microdiffraction stage, with $z$-(vertical) axis adjustment and controlled $X-Y$ movements but with no possibility to rotate it (Fig. 2). Additionally, the tilting of the samples was used to avoid the preferred orientation and the coarse grain effects as it is recommended in [10]. Calculations of the austenite content $V_{\gamma}$ were done using the Averbach-Cohen method according to the formulae [10]:

$$
\begin{aligned}
& V_{\gamma}=\frac{\frac{1}{n_{\gamma}} \sum \frac{I_{\gamma}^{h k l}}{R_{\gamma}^{h k l}}}{\frac{1}{n_{\alpha}} \sum \frac{I_{\alpha}^{h k l}}{R_{\alpha}^{h k l}}+\frac{1}{n_{\gamma}} \sum \frac{I_{\gamma}^{h k l}}{R_{\gamma}^{h k l}}}, \\
& R_{i}^{h k l}=\frac{1}{v^{2}}\left|F_{i}(h k l)\right|^{2} M_{h k l} L P \mathrm{e}^{-2 M}
\end{aligned}
$$

where $I_{i}^{h k l}$ - an integrated experimental intensity of reflection (hkl) of phase $i, n$ - number of measured reflections, $\gamma$ - austenite, $\alpha$ - martensite or ferrite, $v$ volume of the unit cell of phase $i, F_{i}(h k l)$ - the structure factor for reflection $h k l$ of phase $i, M_{h k l}$ - multiplicity factor of reflection $(h k l), \mathrm{LP}$ - the Lorentz polarization factor, $\mathrm{e}^{-2 M}$ - temperature factor. The experimental integral intensity of each reflection was determined using the HighScore Plus software package (PANalytical, The Netherlands, V. 3.0) and pseudo-Voigt function to fit the shape of the reflections. The microstructures of the samples were studied using an optical, digital microscope OLYMPUS DSX500i and electron scanning microscope Inspect $\mathrm{F}$ with a SE (secondary electrons) and a BSE (back scattered electrons) detectors and the EBSD (electron back-scattered diffraction) technique.

\section{Results and conclusions}

As an example, microstructures (light microscopy LM, scanning microscopy with SE detector SEM-SE) of the A clinching joint for the undeformed and deformed parts are shown in Table $\mathrm{V}$. The undeformed part in every joint is characterized by almost equiaxial grains. The grains of the walls parts of the upper sheet of every joint have got the similar, strongly deformed structure. The level of deformation in the lower sheet is not so strong as in the upper sheet, the direction of elongation of the grains is also different. At the bottom parts of the joints, the elongation of grains is similar in the upper and the lower sheet, but is more pronounced for C and D samples, both

TABLE V

Microstructures (light microscopy - LM, scanning electron microscopy - SEM, SE detector) of upper and lower parts of the "A" clinching joint.

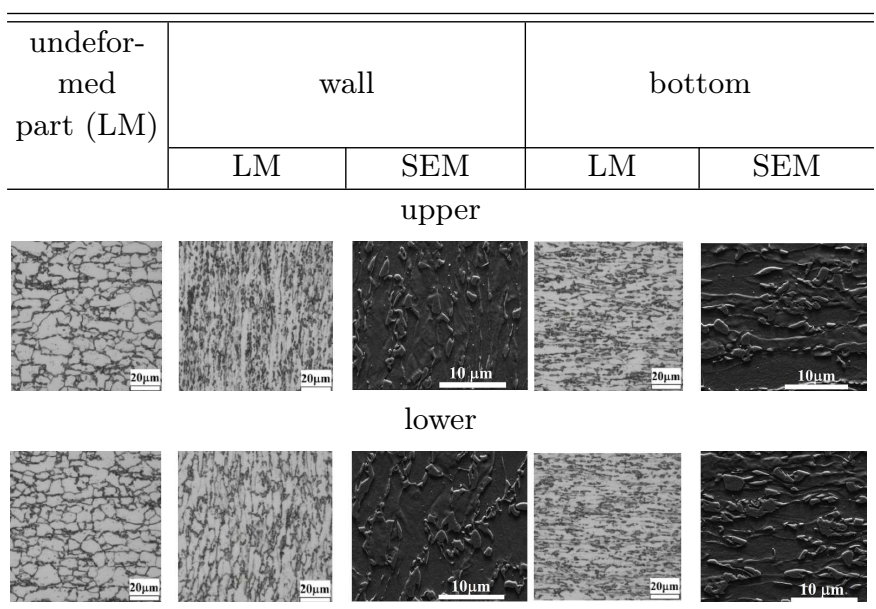


TABLE VI

Austenite contents [vol.\%] in different parts of the clinching joints (micro-XRD results).

\begin{tabular}{c|c|c|c|c|c}
\hline \hline Sample & undeformed & \multicolumn{2}{|c|}{ wall } & \multicolumn{2}{c}{ bottom } \\
\cline { 3 - 6 } & part & upper & lower & upper & lower \\
\hline $\mathrm{A}$ & 3.77 & 0.66 & 0.69 & 0.63 & 0.48 \\
$\mathrm{~B}$ & 3.66 & 0.92 & 0.62 & 1.09 & 0.71 \\
$\mathrm{C}$ & 3.28 & 0.45 & 0.20 & 0.46 & 0.24 \\
$\mathrm{D}$ & 3.72 & 0.71 & 0.94 & 0.77 & 0.91
\end{tabular}

forming with punch diameter of $4.8 \mathrm{~mm}$. The XRD results showing austenite contents in different parts of the examined clinching joints are presented in Table VI and the results of fitting the reflections are shown in Fig. 3. The average austenite fraction in undeformed parts is $3.61 \mathrm{vol} \%$ (the mean value of four measurements in four joints). Austenite contents in every deformed part, but with a different tendency, depending on the forming conditions, decrease significantly. The observed variations in austenite content in the upper sheet are of the same order for both the wall and the bottom areas (joints B, C, D). For the same joints, the similar dependence can be observed for the lower sheet. The comparison of two joints $\mathrm{B}$ and $\mathrm{C}$ with the same embossment thickness $d=0.75 \mathrm{~mm}$ shows that decrease of the punch diameter (from 5.2 to $4.8 \mathrm{~mm}$ ) lowers the austenite content in the walls and in the bottoms as well. In sample A, with the highest forming force, of the punch diameter and of the embossment thickness, the tendency is quite different. Almost the same values of the austenite fraction are observed in the walls and in the bottom parts of upper and lower sheets (Fig. 4).

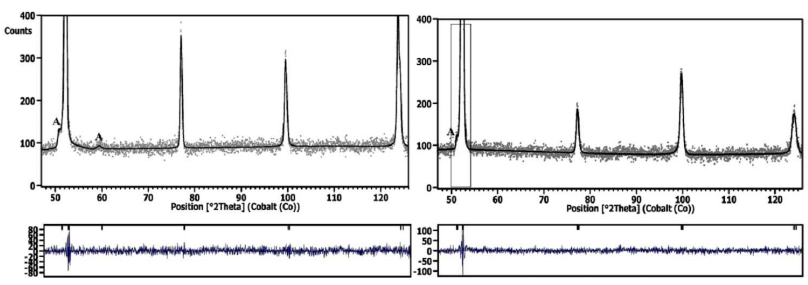

Fig. 3. Measured (points) and calculated (solid line) X-ray diffraction patterns for the undeformed (left) and deformed area (right) of the clinching joint of A sample and difference plots (below). The positions of analysed reflections are marked above the difference plots. The letter $\mathrm{A}$ is related to austenite reflections. The other peaks are ferrite/martensite reflections. No reflections indicating the presence of tetragonal martensite were observed and there was no possibility to resolve ferrite and martensite reflections. The marked area in the right diffraction pattern is shown in right part of Fig. 4 with the results of fitting of two overlapped reflections of $(111)_{\text {austenite }}$ and $(110)_{\text {ferrite/martensite }}$.

In summary, X-ray micro-diffraction technique was used to observe the changes in austenite content depending on forming conditions of clinching joints. The importance of this application consists in ability to study
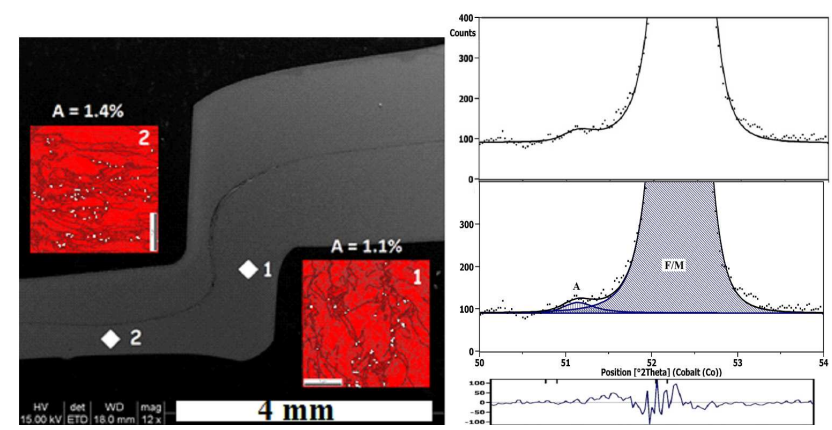

Fig. 4. Left: the SEM micrograph (BSE detector) of the half of the clinching joint of A sample (grey); resin black. The white marks on the surface of the joint indicate the approximate positions of the areas investigated by EBSD technique. The results of the analysis are shown in the two insets, showing the surface distribution of the grains of alpha phase (ferrite and martensite) and of gamma phase (austenite), the latter seen as the very small white grains. In the micrograph, the A means the surface fraction of austenite content. Upper right: the result of fitting pseudo-Voigt functions (solid line) of the XRD reflections representing the ferrite/martensite and austenite strongest reflections to the experimental pattern (dots); right in the middle: fitting of individual peaks of austenite (A) and ferrite/martensite $(\mathrm{F} / \mathrm{M})$; right at the bottom: the difference plot. The experimental pattern was collected in the area no. 2 .

amounts of austenite such as below 1 vol.\% in very small areas in deformed and undeformed parts of clinching joints.

\section{Acknowledgments}

The authors would like to thank Dr. K. Radwański for providing the EBSD results and Z. Kania, MSc., for her help in X-ray measurements.

\section{References}

[1] R. Neugebauer, M. Todtermuschke, R. Mauermann, F. Riedel, Archiv. Civ. Mech. Eng. 8, 4 (2008).

[2] J. Mucha, L. Kaščák, E. Spišák, Adv. Mech. Eng. 2013, 1 (2013).

[3] J. Mucha, W. Witkowski, Thin Wall. Struct. 82, 55 (2014).

[4] F. Lambiase, A. Di Ilio, A. Paoletti, Int. J. Adv. Manufact. Technol. 77, 5 (2015).

[5] J. Mucha, Mater. Des. 32, 4943 (2011).

[6] A. Grajcar, H. Krztoń, J. Achiev. Mater. Manufact. Eng. 35, 169 (2009).

[7] J. Gibmeier, N. Rode, R. Lin Peng, M. Odén, B. Scholtes, Appl. Phys. A 74, s1440 (2002).

[8] R. Lin Peng, N. Rode, M. Odén, J. Gibmeier, B. Scholtes, Mater. Sci. Technol. 19, 3 (2003).

[9] H.J. Krztoń, M. Niesler, Z. Kania, Powder Diffr. 28, S133 (2013)

[10] Ch.F. Jatczak, J.A. Larson, S.W. Shin, SAE Technical Paper 800426, SP-453 (1980). 